\title{
MATERIAL DIDÁTICO PARA ENSINO DE TALIAN COMO LÍNGUA DE HERANÇA NO BRASIL
}

\author{
Pedagogical Material for Teaching Talian as Language of Heritage in \\ Brazil
}

\author{
Luciana Lanhi BALTHAZAR \\ Universidade Federal do Paraná \\ lucianallbb@ufpr.br \\ https://orcid.org/0000-0001-7159-3788 \\ Jovania Maria PERIN SANTOS \\ Universidade Federal do Paraná \\ jovaniaperinsantos@gmail.com \\ http://orcid.org/0000-0002-6639-2559
}

\begin{abstract}
RESUMO: O objetivo deste artigo é apresentar um material didático para o ensino de Talian como língua de herança (ORTALE, 2016) no Brasil. O Talian é falado em alguns estados brasileiros cuja imigração foi predominantemente da região do Vêneto, Itália. A produção do material didático está ligada ao CEVEP (Centro de Estudos Vênetos no Paraná), grupo de pesquisa que tem como objetivo principal a salvaguarda dessa língua e dessa cultura. A fundamentação teórica subjacente ao material está associada à abordagem por tarefas (ELLIS, 2003) e à abordagem intercultural(FREIRE, 1992,1993,2001). Nesteartigo serãoapresentadas também algumas especificidades desse material, como por exemplo: a presença dos falantes das comunidades do Paraná como participantes na produção de todos os textos orais e escritos; o contexto de utilização do material e seu público-alvo. Além disso, vamos descrever algumas etapas da elaboração das unidades didáticas que fazem parte do material. PALAVRAS-CHAVE: CEVEP; Material didático; Talian; Língua de herança.
\end{abstract}

\begin{abstract}
The purpose of this article is to present a pedagogical material for teaching Talian as a heritage language (ORTALE, 2016) in Brazil. Talian is spoken in some Brazilian states whose immigration was predominantly from the Veneto region, Italy. The production of pedagogical material is linked to CEVEP (Centro de Estudos Vênetos no Paraná), a research group whose main objective is to safeguard this language and culture. The theoretical foundation is to safeguard and enhance this language and culture. The theoretical foundation underlying the material is associated with the task approach (ELLIS,
\end{abstract}


2003) and the intercultural approach (FREIRE, 1992, 1993, 2001). This article will also present some specificities of this material, such as: the presence of speakers from the communities of Paraná as participants of all oral and written texts; the context of the material and its target audience. In addition, we will describe some steps in the presentation of the didactic units that are part of the material. KEYWORDS: CEVEP; Pedagogical material; Talian; Heritage language.

RESUMO: Quelo che se vole con questo artigo ze presentar un material didàtico par el insegno del Talian come léngua de eredità (ORTALE, 2016) ntel Brasile. El Talian ze parlà in alcuni stadi brasiliani ndove ze imigrà tanta gente dela Region del Véneto, Itàlia. A produssion de questo material didàtico ze ligà al CEVEP (Sentro de Studii Veneti ntel Paranà), grupo de studii che ga come el so grande lavoro la salvaguàrdia de questa léngua e de questa cultura. La fondamentassion teòrica che fà la base de questo material se someia a quele del insegnamento par tarefe (ELLIS, 2003) e a insegnamento intercultural (FREIRE, 1992, 1993, 2001). Sun questo artigo va esser anca presentate alcune particolarità de questo material, come a participassion dei parlanti dele comunità del Paranà come fornitori de tuti i testi orali e scriti; el posto de utilisassion del material e par chi che el ze fato. Dopo ancora demo descriver alcuni passi dela elaborassion dele unità didàtiche che fano parte del material. PAROLECIAVE: CEVEP; Material didàtico; Talian; Léngua de eredità.

\section{INTRODUÇÃO}

O Centro de Estudos Vênetos no Paraná (CEVEP) é um grupo de pesquisa multidisciplinar cadastrado no CNPq desde 2008. Fazem parte pesquisadores e alunos das áreas de Linguística, Arquitetura, Pedagogia, História, Direito e Design destas instituições: Unicentro, UFPR, PUC-PR, IPHAN-PR, Comunidade Italiana de Campo Largo, Colombo e Museu Municipal Cristóforo Colombo, de Colombo, Paraná. Dada a diversidade dos participantes e a variedade dos interesses, a colaboração dos membros do centro é articulada em diversos projetos, dentre eles: a) entrevistas sociolinguísticas em Talian; b) preparação de material didático para o ensino do Talian; c) representação/ divulgação do grupo em eventos voltados à comunidade; d) produção do "Dicionário do Talian falado em Curitiba e região metropolitana" dentre outras. 
O principal objetivo do CEVEP é a salvaguarda da língua Talian, ou seja, todas as iniciativas têm como objetivo a manutenção, a preservação ${ }^{1}$ e a valorização da língua. Entendemos Talian como língua que se forma no Brasil a partir da necessidade de comunicação entre os imigrantes italianos que aqui chegaram, no final do século XIX, falando as mais diversas línguas. O Brasil recebeu imigrantes de várias regiões italianas, em sua maioria, vênetos (BALHANA, 1978). Portanto, é natural que o Talian seja uma língua de base vêneta ${ }^{2}$, mesmo que em algumas regiões brasileiras possam existir influências de outras línguas do norte da Itália. É importante ressaltar, entretanto, que o Talian não é a mesma língua falada na região do Vêneto, na Itália. De fato, diferente da língua vêneta, o Talian teve, e ainda tem, contato com o português brasileiro.

Sendo assim, podemos definir o Talian ${ }^{3}$ como uma língua nascida no Brasil, de base vêneta formada pelo contato linguístico com o português brasileiro e com outras línguas aqui faladas. É uma língua predominantemente oral e falada sobretudo em regiões com presença de descendentes de italianos. Como qualquer outra língua, o Talian sofre variações. Portanto, é natural que o Talian falado no Paraná, em Santa Catarina, no Rio Grande do Sul, no Espírito Santo ou em qualquer outro lugar do Brasil apresente diferenças. As variantes são compreendidas como "diversas maneiras de dizer a mesma coisa em um mesmo contexto e com o mesmo valor de verdade" (TARALLO, 1985, p. 7). Portanto, poderíamos considerar, por exemplo, famegia e fameia duas variantes do Talian falado em Curitiba e região para a palavra "família". Atualmente as duas variantes estão

\footnotetext{
${ }^{1} \mathrm{O}$ uso das palavras "manutenção" e "preservação" neste trabalho não implica a adoção de um conceito de língua como um sistema estático.

${ }^{2}$ Base vêneta significa que o Talian no Brasil foi formado a partir, prevalentemente, dos dialetos provenientes do que hoje conhecemos como região do Vêneto, na Itália. A região é formada por sete províncias, a saber: Veneza, Treviso, Belluno, Vicenza, Pádua, Verona e Rovigo. No Paraná, por exemplo, a maior parte dos imigrantes italianos eram vicentinos e trevisanos (BALHANA, 1978), portanto, também a língua Talian do PR tem grandes influências dessas duas províncias vênetas. Vale ressaltar, como já dito, que embora a base seja vêneta é o contato linguístico com o português brasileiro que diferencia o Talian da língua vêneta.
}

${ }^{3}$ Com a publicação do Decreto 7.387/2010, o Talian é reconhecido como Referência Cultural Brasileira pelo Instituto do Patrimônio Histórico e Artístico Nacional (Iphan) e passa a fazer parte do Inventário Nacional da Diversidade Linguística (INDL). Vale dizer que nem todos os seus falantes a denominam "Talian", dentre as diversas nomenclaturas para designar a mesma língua falada aqui no Brasil, podemos encontrar: dialeto vêneto, italiano, vêneto brasileiro, dialeto, dialeto italiano, entre outras. O próprio INDL cita estas e outras denominações. Entretanto, por questões de políticas linguísticas e pensando no fortalecimento da própria língua a nível nacional, os membros do grupo CEVEP também a denominam de Talian. 
em uso, famegia é mais comum na cidade de Colombo-PR e fameia mais usual no Bairro Santa Felicidade, em Curitiba.

Outro conceito importante a ser esclarecido para entender a produção do presente material didático é a definição de "língua de herança". De acordo com o entendimento do grupo CEVEP, o Talian no Brasil pode ser considerado uma língua de herança, ou seja:

língua com a qual uma pessoa possui identificação cultural e sentimento de pertencimento a determinada comunidade que a usa, seja por laços ancestrais, seja por convivência no mesmo ambiente sociocultural com falantes dessa língua (ORTALE, 2016, p. 27).

O primeiro ponto relevante ao levar em consideração a definição anterior é que o ensino de língua de herança prevê alunos com ou sem ancestralidade italiana. $\mathrm{O}$ fator ancestralidade pode estar ligado a muitos alunos no Brasil, mas não é o único. De fato, na elaboração do presente material didático foi levada em consideração não somente a ancestralidade, mas também o ambiente no qual o Talian é falado, ou seja, terras brasileiras. Por outro lado, tendo em vista a formação histórica e social desta língua é natural que descendentes de italianos se interessem pelo Talian. É comum, por exemplo, encontrar em comunidades ítalo-brasileiras pessoas que aprenderam Talian até mesmo antes de aprender português brasileiro. Ou ainda, aqueles que o falam, sobretudo com os familiares, sem nenhuma dificuldade. Nestes casos o material didático pode ser usado como proposta de manutenção desta língua que, atualmente, nem sempre encontra grande espaço nas comunidades, ou ainda, como proposta para debater aspectos linguísticos do Talian ligados à identidade dos falantes, como por exemplo: orgulho, vergonha, variações, preconceito linguístico etc.

Uma implicação relevante ao entender Talian como língua de herança no Brasil diz respeitos a nós, pesquisadores brasileiros. A responsabilidade da produção, da análise e do ensino, nesta visão, está relacionada a professores e linguistas brasileiros. Se defendemos a língua Talian como língua que nasce em terras brasileiras, somos nós, linguistas do Brasil engajados com produção de materiais didáticos e metodologia de ensino os responsáveis por esta tarefa. Esse posicionamento está alinhado com a perspectiva da produção de materiais didáticos específicos para públicos específicos, pois isso permite a adequação das propostas de ensino às necessidades dos alunos e à realidade sociocultural em que eles circulam. Os materiais didáticos para ensino de línguas estrangeiras feitos para atender vários públicos e ainda sem adequada aproximação às vivências dos alunos constituem-se materiais com baixa interlocução e consequentemente pouco relevantes. 
Quando elaboramos atividades considerando as especificidades de nossos estudantes temos muito mais chance de despertar sua atenção e a vontade de interagir. Além é claro, de explorarmos as dificuldades de aprendizagem que são frequentes para cada público.

No que se refere ao ensino de língua de herança há ainda mais a necessidade de direcionar os conteúdos a fim de contemplar vivências e demandas comunicativas que sejam representativas. Nessa realidade é importante que os alunos se identifiquem com o que é mostrado e isso irá acontecer através dos contextos históricos, sociais, culturais e linguísticos contemplados no material.

\section{FUNDAMENTAÇÃO TEÓRICA}

\section{Contribuição da abordagem comunicativa}

Para compreendermos as abordagens subjacentes ao material didático em questão, precisamos retomar alguns construtos que deram base epistemológica para a abordagem comunicativa. Estamos considerando como base teórica para a abordagem comunicativa importantes direcionamentos apresentados ainda na década de 1970 do século XX influenciados por estudos na área da sociolinguística. O linguista Dell Hymes (1972) foi um dos grandes expoentes dos estudos comunicativos. São desse autor os conceitos centrais dessa abordagem: os aspectos culturais e sociais da linguagem. Sua argumentação considerava que para um falante ser entendido como competente ele não poderia apenas dominar as estruturas gramaticais de uma língua, mas teria que compreender como usar essa língua nos contextos sociais. Isso contribuiu para uma mudança de foco nas pesquisas da linguística, distanciando-se dos estudos que priorizavam o domínio das estruturas gramaticais.

Atualmente o ensino-aprendizagem de línguas apresenta de modo significativo os construtos comunicativos, seja nas diferentes abordagens, nas metodologias, nas práticas de ensino, na formação dos professores e na elaboração de materiais didáticos. Ao longo das últimas décadas vários autores têm contribuído e ampliado essa perspectiva de estudos, apresentando novas vertentes e construtos teóricos pautados na visão comunicativa. A abordagem por tarefas e a abordagem intercultural estão entre essas vertentes, as quais formam a base teórica para o desenvolvimento dos materiais didáticos de Talian que temos confeccionado. 


\section{Abordagem por tarefas}

A linguística aplicada, área interdisciplinar que desenvolve muitos estudos sobre o ensino-aprendizagem de línguas, tem presenciado desde a década de 1980 investigações denominadas como abordagem por tarefas. As publicações de N. S. Prabhu (1987) e David Nunan (1989) marcaram o início dessa abordagem. O linguista indiano Prabhu realizou um projeto de ensino de língua na Índia no qual foram utilizadas, de forma pioneira, tarefas. De acordo com Santos (2014, p. 17) "nesse projeto o direcionamento era para o significado e procurava-se evitar a pré-seleção da linguagem e atividades focalizadas na forma ${ }^{4}$. Acreditava-se que a forma seria aprendida de modo mais efetivo quando a atenção dos alunos estivesse voltada para o significado". Outro expoente da abordagem por tarefas foi Nunan (1989), o linguista australiano forneceu orientações práticas para o design e desenvolvimento de tarefas no livro Designing tasks for the communicative classroom. Nessa obra o autor apresenta "cinco variáveis que devem ser levadas em conta para a análise de uma tarefa: objetivos, insumo, atividades, papel do professor, papel do aluno e contexto" (SANTOS, 2014, p. 17). Outros autores que contribuíram significativamente para a constituição e desenvolvimento dessa abordagem são Jane Willis (1996), Rod Ellis (2003) e Sheila Estaire (2009).

A palavra "tarefa" assume, nesse contexto, um papel central e a conotação atribuída a essa palavra diferencia-se do sentido comum que em geral estamos acostumados a usar. Nas práticas escolares "tarefa" refere-se aos trabalhos (atividades ou exercícios) a serem feitos em casa - as famosas "tarefas de casa" -, mas na abordagem por tarefas não é usada com esse sentido. As tarefas são propostas de ensino voltadas a favorecer a prática da língua-alvo em situações comunicativas. Através dessas propostas temos, de forma organizada, um modo de envolver os estudantes a fim de que resolvam problemas e interajam de maneira muito próxima às circunstâncias que encontrariam no mundo real, ou seja, nas vivências fora de sala de aula. De acordo com Xavier (2008, p. 23) o uso da língua "só faz sentido dentro de um contexto, fazendo parte de um discurso, já que a linguagem se caracteriza como uma prática social”.

No entanto, temos visto na literatura da área algumas variações quanto à definição de tarefa. De acordo com Nunan (1989, p. 10), as tarefas constituem "uma parte do trabalho realizado em sala de aula que envolve os alunos na compreensão, manipulação, produção ou interação na língua-alvo enquanto a atenção está principalmente focalizada

\footnotetext{
${ }^{4}$ A palavra "forma" nessa citação refere-se a estruturas gramaticais de uma língua as quais aparecem na literatura também como "recursos linguísticos".
} 
no significado em vez da forma". Este conceito está diretamente ligado à proposta fundamental da abordagem comunicativa que é a prioridade no significado em detrimento da sistematização de estruturas linguísticas. Segundo Ellis (2003, p. 16) a tarefa é

\begin{abstract}
um plano de trabalho que requer que os alunos processem a linguagem pragmaticamente, a fim de alcançar um resultado que pode ser avaliado em termos de saber se o conteúdo foi transmitido. Com este fim, a tarefa exige do aprendiz atenção primária ao significado e uso de seus próprios recursos linguísticos, embora o design de uma tarefa possa prever escolhas linguísticas particulares. Uma tarefa é entendida como o resultado da língua em uso que tem uma semelhança, direta ou indireta, com a forma como a linguagem é usada no mundo real. Como outras atividades linguísticas, a tarefa pode envolver habilidade produtiva ou receptiva, e oral ou escrita, e também processos cognitivos diversos.
\end{abstract}

No conceito apresentado por Ellis vemos a preocupação com o uso da linguagem no mundo real e há também a menção aos recursos linguísticas, com essa expressão podemos subentender as estruturas da língua, porém a atenção primária está voltada ao significado. Com isso o autor destaca a primazia na parte contextual/sociocultural, mas leva em conta que são necessários recursos linguísticos para a elaboração das tarefas. Ainda vemos no final da citação a abrangência das tarefas, podendo incluir também processos cognitivos.

Para que uma abordagem como essa seja colocada em funcionamento é necessário que alguns paradigmas, fortemente consolidados no ensino-aprendizagem de línguas, sejam revistos. É o caso da sequência em que os conteúdos aparecem nos cursos e nos materiais didáticos. Se queremos confeccionar atividades que estejam de acordo com a abordagem por tarefas não vamos planejar um curso ou uma unidade didática a partir de conteúdos gramaticais. Ao invés disso, o objetivo principal será, por exemplo, explorar situações socioculturais que os alunos certamente vivenciam como: apresentar-se; falar sobre si (nome, profissão, lugar de nascimento, endereço, etc.); expressar gostos e preferências, entre outros. Para realizar tarefas com essa finalidade, certamente recursos linguísticos (vocabulário, tempos verbais, pronomes, preposições, artigos, advérbios, adjetivos), assim como a pronúncia e entonação) deverão ser mobilizados pelos alunos, mas não significa que esses recursos precisam ser explorados todos de uma vez e nem mesmo que serão o ponto central. As propostas partem das situações socioculturais e do que se pressupõe que os alunos já conhecem ou terão condições de produzir e "gradualmente" novos conteúdos serão apresentados e explorados. Conforme resumem Luce e Finger (2008, p. 21-22) uma tarefa 
deve permitir ampla oportunidade de uso e rica exposição à língua alvo, através de etapas que permitam interação entre os aprendizes; deve ser desafiante e motivadora, o que se torna possível devido à existência de um objetivo a ser atingido (goal); e, finalmente, deve ter livre uso da língua alvo, isto é, o aprendiz não deve ficar condicionado ao uso de uma forma específica para atingir a meta comunicativa da tarefa.

A abordagem por tarefas pode ser aplicada em diferentes formatos, estamos nos referindo a como as tarefas se apresentam nos materiais didáticos. Isso poderá acontecer em tarefas individuais, em unidades didáticas ou unidades temáticas, em sequências didáticas ou como parte de um projeto pedagógico. As unidades didáticas e as unidades temáticas se assemelham bastante e muitas vezes são consideradas como equivalentes. Trata-se de propostas de ensino voltadas à prática comunicativa, à exploração das várias habilidades linguísticas e culturais.

O desenvolvimento de propostas que explorem questões culturais é muito importante para o ensino de línguas e especialmente para o ensino de língua de herança. Por essa razão, incluímos, no material didático elaborado, atividades que visam contribuir sobretudo para o relato de experiências culturais e para nos nortear nesse sentido, iremos discorrer na sequência sobre a base teórica da abordagem intercultural.

\section{Abordagem intercultural}

Desde que o termo 'competência comunicativa' é cunhado por Dell Hymes (1972), já existe a ideia que o conhecimento de uma língua não se reduz apenas ao conhecimento de sua gramática. De fato, saber uma língua passa também pela competência do uso apropriado da língua de acordo com a comunidade na qual se vive. A preocupação com o uso social da língua e seus aspectos culturais também influem na comunicação. Por isso, atualmente é comum encontrar, sobretudo em estudos relacionados à linguística aplicada, a componente intercultural como uma das componentes da 'competência comunicativa'. Para Balboni, linguista italiano ligado a pesquisas sobre o ensino/aprendizagem de italiano como língua estrangeira, "a competência cultural indica a capacidade de se comunicar de maneira apropriada no contexto cultural no qual se realiza o evento comunicativo" (BALBONI, 1999, p. 20, tradução nossa). Mais uma vez, portanto, entra em jogo a importância do contexto no qual a língua é falada para a definição da competência intercultural.

Percebe-se, portanto, que os conceitos teóricos relacionados à abordagem intercultural pressupõem que língua e cultura são indissociáveis. De fato, é através da 
língua que as práticas culturais de um povo tomam sentido, são os falantes que atribuem sentidos ao que chamamos de 'cultura'. A língua não é um sistema arbitrário de formas linguísticas, a língua faz sentido quando aplicada a uma realidade cultural, ao mundo real (KRAMSCH, 2017).

Dentro da perspectiva intercultural, ao entrar em contato com a língua estudada, o aluno entra em contato também com outras representações que podem auxiliá-lo não só a enxergar mais criticamente o seu mundo, mas também a perceber suas próprias práticas culturais. Esta observação de si mesmo através do estudo de uma língua estrangeira é chamada de 'terceiro lugar' por Kramsch (1993). Para a autora, quando o aluno entra em contato com outras representações culturais ele enxerga a sua com outro olhar, nas suas palavras os alunos ocupam "uma posição em que se veem de dentro e de fora". Para ela, "alunos de línguas aprendem quem são por meio do seu encontro com o Outro" (KRAMSCH, 2017, p. 5). Tal conceito evidencia o diálogo entre a cultura do aluno (C1) e a cultura da língua estudada (C2). Dentre os objetivos deste tipo de ensino podemos citar: "a) encontrar um fenômeno equivalente em $\mathrm{C} 1$ e construir o fenômeno na $\mathrm{C} 1$ com suas próprias redes de significado". E ainda: b) “examinar o modo como as percepções de $\mathrm{C} 1$ e $\mathrm{C} 2$ em parte determinam as percepções que estrangeiros têm delas, i.e. o modo como cada cultura vê a outra" (KRAMSCH, 1993).

Entretanto, a realidade do Talian como língua de herança no Brasil nos faz analisar se estes e outros objetivos apoiados nesta perspectiva seriam pertinentes. Embora o Talian seja uma língua e o português brasileiro outra, seus falantes ou alunos vivem todos em um único país, o Brasil. Em alguns momentos é difícil "examinar as percepções diferentes" porque elas convergem, são as mesmas. Nossa conclusão é que o estudo de língua de herança no Brasil apresenta especificidades diferentes do ensino de língua estrangeira. Para compreender como pode se dar o ensino do Talian através de uma abordagem intercultural é necessário analisar onde e por quem esta língua é falada.

O Talian no Brasil pode ser encontrado sobretudo em regiões com colonização italiana, em comunidades espalhadas, sobretudo, pelos estados do Espírito Santo, Paraná, Santa Cataria e Rio Grande do Sul. As práticas culturais das cidades com a presença do Talian são, muitas vezes, embora as diferenças geográficas, muito similares. De fato, não somente a língua falada é a mesma, embora com variações, mas também as manifestações relacionadas à cultura ${ }^{5}$. Se por um lado tais afirmações corroboram a ideia de língua e

\footnotetext{
${ }^{5}$ A definição de cultura é muito ampla e pode ser compreendida a partir de diversas ciências, como a Sociologia, Educação, Linguística, dentre outras. Para este artigo, apoiadas em Laraia (1986), entende-se cultura a partir de uma visão antropológica como todo o conjunto de crenças, hábitos, formas de vestir, pensar, agir e falar que é passado, vivido e compartilhado entre as pessoas.
} 
cultura serem indissociáveis, por outro, nos levam a direcionar nossos olhares para as semelhanças culturais entre as comunidades com a presença do Talian no Brasil, não as diferenças. De fato, é através desse trabalho com as similaridades que é possível construir uma "unidade na diversidade", como nos demonstra Freire:

As chamadas minorias, por exemplo, precisam reconhecer que, no fundo, elas são a maioria. O caminho para assumir-se como maioria está em trabalhar as semelhanças entre si e não só as diferenças e assim criar a unidade na diversidade, fora da qual não vejo como aperfeiçoar-se e até como construir-se uma democracia substantiva, radical (FREIRE, 1992, p. 78).

Seguindo a definição acima, podemos concluir que talvez para alcançar a "unidade na diversidade" dentro da realidade do Talian, seja necessário trabalhar com a observação e percepção de aspectos culturais semelhantes entre estas comunidades no Brasil. Um material didático que apresente aspectos culturais destas comunidades "minoritárias" brasileiras pode promover esta oportunidade de observação. $\mathrm{O}$ autor destaca ainda que a"[...] busca na unidade na diferença, a luta por ela, como processo, significa já o começo da criação da multiculturalidade [...]" (FREIRE, 1993, p. 157).

Com efeito, a multiculturalidade apresentada por Paulo Freire pode auxiliar a compreender o complexo quadro cultural que exige o ensino de Talian no Brasil.

Paulo Freire situa a multiculturalidade no processo de libertação, que não se caracteriza pela sobreposição de culturas, mas sim: [...] na liberdade conquistada, no direito assegurado de mover-se cada cultura no respeito uma da outra, correndo risco livremente de ser diferente, sem medo de ser diferente, de ser cada uma "para si", somente como se faz possível crescerem juntas [...] (FREIRE, 1993, p. 79, grifos do autor).

A perspectiva freiriana converge com a realidade do Talian no Brasil porque assegura e legitima as diferenças culturais provenientes das 'comunidades talianas' ${ }^{6}$ espalhadas pelo Brasil e, ao mesmo tempo, reforça que o crescimento deve ser coletivo, ou seja, é o fortalecimento de todas as variedades linguísticas talianas presentes no nosso país que fortalecerá a língua Talian nacionalmente. Portanto, é somente através de um ensino de Talian que respeite estas variedades presentes no país e as diferentes "identidades talianas" provenientes de tais variedades que se dará o fortalecimento desta língua.

\footnotetext{
6 "Taliana" aqui refere-se às comunidades nas quais se falam "Talian" e foi utilizado desta forma com o objetivo de reforçar que a língua falada é o Talian e não o italiano standard ou a língua vêneta.
} 
O respeito à identidade do Outro, da cultura do Outro, definida para Freire como "identidade cultural" implica no "[...] respeito pela linguagem do outro, pela cor do outro, o gênero do outro, a classe do outro, a orientação sexual do outro, a capacidade intelectual do outro [...]" (FREIRE, 2001, p. 60, grifo nosso). Vale ressaltar que respeitar a identidade cultural do Outro pressupõe o reconhecimento de sua identidade cultural. É extremamente importante, portanto que um material didático que preze pelo respeito às diferentes identidades culturais, colabore com a percepção e a observação da sua própria identidade cultural. Com efeito, o ensino/aprendizagem de outras línguas pode auxiliar nesse processo, como afirma Rajagopalan (2003, p. 69): “as línguas são a própria expressão das identidades de quem delas se apropria. Logo, quem transita entre diversos idiomas está redefinindo sua própria identidade".

O trabalho de percepção e de valorização da identidade taliana no Brasil perpassa todo o processo social e histórico de constituição desta língua. Diversos trabalhos $\operatorname{acadêmicos}^{7}$ já demonstraram a existência de sentimentos de vergonha e preconceito linguístico em relação à "identificação taliana" e, consequentemente, ao Talian. Para propiciar a reflexão sobre aspectos identitários talianos é necessário conhecer o processo histórico, social e cultural dos seus falantes. Este panorama nos leva a refletir, por exemplo, sobre a atenção para a manutenção da talianidade brasileira sem depreciar ou deixar de lado as origens vênetas. É necessário que se tome consciência do quanto a identidade dos falantes de Talian está conectada às terras brasileiras sem, de maneira alguma, negar a importância histórica, cultural e linguística dos vênetos. Não se pode absolutizar a cultura taliana brasileira com um único parâmetro vêneto a ponto de desconsiderar todo o contexto brasileiro no qual ela está inserida. Neste sentido, mais uma vez o conceito de interculturalidade crítica de Paulo Freire converge com a realidade do Talian no Brasil:

Muita gente já deve ter dito o que vou dizer agora. Percebi quão fortes são as nossas marcas culturais. Mas quão mais fortes elas se tornam na medida em que não as idealizamos. Na verdade, no momento em que começas a dizer: não, tudo o que é bom, só é chileno, as marcas da tua cultura enfraquecem. Mas, na medida em que, em lugar da idealização das tuas marcas, tu as tratas bem, cuidas delas seriamente, sem absolutizá-las, então percebes que, sem elas, te seria difícil, inclusive, receber outras marcas que, ao lado de tua história pessoal, fossem significativas (FREIRE; FAUNDEZ, 1985, p. 17).

\footnotetext{
${ }^{7}$ Para estudos em Santa Catarina ver BALTHAZAR, 2016; para Rio Grande do Sul ver FROSI et al., 2010, livro no qual as autoras gaúchas reúnem artigos relacionados ao 'Estigma' à língua italiana falada na região.
} 
Freire afirma ainda, que sem as marcas da sua cultura que o identificam, e dentre elas nós citamos a língua, ele se tornaria "um puro vagar no mundo, sem quase razão de ser" (FREIRE; FAUNDEZ, 1985, p. 17). Com efeito, questões identitárias estão fortemente conectadas às percepções pessoais que, por sua vez, perpassam questões linguísticas. Um material didático fundamentado nas supracitadas teorias certamente deverá levar em consideração todas estas questões de identidade taliana, língua e cultura taliana, língua e cultura vêneta e língua e cultura do português brasileiro.

\section{APRESENTAÇÃO DO MATERIAL}

Tendo em vista os objetivos do grupo de pesquisa CEVEP, é de suma importância a elaboração de materiais didáticos, pois serão uma ferramenta para a divulgação da língua. Produzir esse tipo de proposta para o ensino de uma língua de herança nos colocou diante de alguns desafios, mesmo porque não existem muitos materiais e muitos estudos voltados especificamente para essa finalidade ${ }^{8}$. Nosso ponto de partida foram as experiências anteriores como elaboradoras de materiais e as pesquisas que já tínhamos realizado, além de leituras a respeito da elaboração de materiais para ensino de língua de herança. Na etapa que antecedeu a confecção, fizemos o levantamento de alguns aspectos práticos que nos pareceram essenciais, que foram: identificação dos contextos de uso do material e considerações em torno do público-alvo; definição de temáticas a serem abordadas nas unidades didáticas e, definição do formato dessas unidades didáticas.

\section{Identificação dos contextos de uso do material e considerações em torno do público- -alvo}

Inicialmente nos concentramos em identificar os prováveis contextos de uso do material para a partir daí traçar os planos do seu desenvolvimento. Os contextos pensados foram vários, entre eles: a) aulas de Talian para quem já sabe a língua, ou falava na infância e quer relembrá-la, ou ainda, para quem deseja aprendê-la; b) aulas de italiano standard em qualquer nível nas quais o professor queira apresentar aos alunos (descendentes de italianos ou não) uma língua de base vêneta e originada no Brasil; c) encontros entre pessoas que consideram para si o Talian como língua de herança, entre outros. No entanto, queremos ressaltar que embora estejamos elaborando um material especificamente para

\footnotetext{
${ }^{8}$ Um trabalho que teve como objetivo a produção de material didático para o ensino de italiano como língua de herança foi Fornasier (2018).
} 
o ensino do Talian é possível que, como todo material didático, seja preciso adaptá-lo ao perfil dos alunos e à realidade local do ensino.

Em relação à faixa etária e ao conhecimento prévio da língua, o material foi pensando para jovens e adultos com conhecimento linguístico em qualquer nível de Talian ${ }^{9}$. Vale ressaltar que para a produção do material o Talian é visto com língua de herança e "a noção de 'aprendiz de língua de herança' não tem como critério a proficiência linguística, mas a sua percepção em relação à identidade, à língua e à sua origem familiar" (ORTALE, 2016, p. 25). Por essa razão as unidades didáticas priorizam propostas destinadas à valorização de situações comunicativas que visam à interação dos participantes.

Um dos desafios desse material tem sido contemplar as variedades do Talian no Brasil falado pelos seus detentores e o caminho encontrado para isso está nas abordagens de ensino que utilizamos, as quais favorecem o dinamismo intrínseco às línguas. Por meio das atividades comunicativas os alunos são convidados a participar de interações em que são fornecidas sugestões de fala apresentadas em diferentes variedades do Talian. Além disso, os alunos são instigados a se expressar na sua variedade, não impondo ou determinando, desse modo, um modelo idealizado. Fazem parte dessas unidades textos de diferentes fontes e lugares justamente para haver diversificação dos falares do Talian. Nesse sentido, todos os vídeos e áudios usados foram produzidos por detentores dessa língua das comunidades de Curitiba, Colombo, Campo Largo, Lapa e Cascavel, além da participação de detentores de outras regiões do Brasil.

O processo de escolha sobre qual seria a língua utilizada nos enunciados das atividades foi uma oportunidade de reflexão sobre a realidade do Talian no Brasil. A princípio pensamos em escrever todo o material em Talian, mas a dificuldade em escolher apenas uma variedade nos levou a outras perguntas: seria pertinente escrever o material didático de acordo com os falantes de Talian apenas do Paraná (Estado do grupo CEVEP)? E ainda: se, mesmo dentro do Paraná existem variações, qual escolher? Diante deste cenário e levando em consideração os contextos de uso, a primeira opção foi escrever o material em português brasileiro. A segunda opção, mais uma vez levando

\footnotetext{
${ }^{9}$ Os materiais didáticos destinados ao ensino de italiano como LE/L2 no Brasil, sobretudo os mais atuais, usam como referência o Quadro Comum de Referência de Língua, criado pelo Conselho da Europa em 2001, na Europa, para a sua graduação linguística. No caso do Talian, além de não ser uma "língua estrangeira", mas sim uma "língua de herança" no Brasil, não seria adequado usar, por exemplo, o QCRL para nivelar seu conteúdo linguístico. Desta forma, como já dito, o material didático foi pensado para qualquer nível linguístico.
} 
em consideração sobretudo os contextos de uso, foi o italiano standard ${ }^{10}$. Essa versão restringe-se a aulas de italiano como língua estrangeira e pode ser usado em qualquer nível (A1 até $\mathrm{C} 2$ ), com alunos individuais ou em grupo, porque o objetivo neste contexto não seria o ensino de italiano, mas a percepção de uma língua falada no Brasil semelhante à língua ensinada ${ }^{11}$.

A tradução das unidades didáticas para o Talian não está descartada como possibilidade de trabalho futuro. Ao contrário, as autoras têm realizado pesquisas e análises de materiais didáticos com base na intercompreensão (DEGACHE; MELO, 2008) com a intenção de encontrar uma alternativa na qual o Talian seja usado como língua nos enunciados, mas que todas as suas variedades e sua variação seja respeitada.

\section{Temática das unidades didáticas}

O material didático para ensino de Talian que estamos desenvolvendo tem sido compilado em unidades didáticas que se destinam a praticar determinadas temáticas relacionadas às áreas de concentração dos estudos do CEVEP, dentre elas: a língua, a família, a religiosidade, a culinária e o trabalho. A essa lista acrescentamos também uma unidade cujo objetivo é discutir com os alunos sobre aspectos sociolinguísticos. Essa unidade difere das outras, pois se destina a reflexões essenciais relacionadas à atitude dos aprendizes de idiomas e ao conceito de língua de herança.

Ao definir um tema para a unidade, levantamos os objetivos sociolinguísticos a serem atingidos, a partir dos quais elaboramos atividades e tarefas que possam levar os alunos a situações de práticas comunicativas. Na unidade didática que apresentamos em anexo (Anexo 1), os temas explorados estão ligados a atividades realizadas no domingo de manhã. Os alunos são assim, convidados a relatar suas experiências cotidianas; a assistir a um vídeo que mostra (em Talian) o que um falante da comunidade costuma fazer aos domingos; a praticar como se diz os dias da semana, cumprimentos, pronomes pessoais e lugares comuns nas cidades.

É possível que nas unidades seguintes o vocabulário e as estruturas que apareceram nessa unidade sejam também retomados, mas isso vai acontecer em outro contexto e possivelmente com outros propósitos.

\footnotetext{
${ }^{10}$ As autoras pretendem fazer a tradução do material para o italiano standard, mas o trabalho ainda não foi iniciado.

${ }^{11}$ Para o uso do material didático durante aulas de língua italiana recomenda-se começar com a unidade didática "Mi parlo Talian" por suas noções sociolinguísticas do conceito de língua e dialeto.
} 


\section{Características das unidades}

A elaboração das unidades didáticas segue uma sequência de subsecções que não necessariamente possuem a mesma ordem, mas são dispostas de maneira a favorecer a realização das tarefas. Essas subsecções são: Interação; Pra começar; Responda em Talian; Compreensão de vídeo; Como se diz em Talian; Refletindo com o Talian; Hora da música; Escuta só.

As tarefas solicitadas aos alunos são, em sua maioria, para a prática da oralidade porque o Talian é predominantemente uma língua oral. Essa é a característica também dos textos que iniciam as atividades, frequentemente vídeos e áudios que, como já dito anteriormente, são elaborados por detentores do Talian. Alguns desses textos nós (as autoras) solicitamos que pessoas da comunidade os produzissem, no entanto, alguns áudios já haviam sido publicados em mídias diversas ou redes sociais e por isso são textos autênticos.

Tanto os vídeos, os áudios, como os textos escritos em Talian que estão presentes no material são representações das variedades dessa língua, compondo uma mescla de falares como se colocássemos em interação, pessoas de diferentes lugares. A todo momento os alunos são convidados a refletir sobre as variações do Talian, e isso pode ser constatado em frases como as da página 1 da unidade didática em anexo: "As pessoas que você ouviu nos áudios falam da mesma forma?"; as da página 3: "Você conhece outras formas de cumprimentar?" ou "Existem variações entre o que você e seu colega falaram? Como você fala 'eu, tu, você, ele, ela, nós, vocês, eles e elas'?"

No final da página 2, há uma atividade em que os alunos são convidados a falar o nome de alguns objetos mostrados no vídeo, mas devem apresentar a sua variedade da língua e comparar com o que aparece no vídeo. Caso os alunos são sejam falantes, esta será uma proposta em que devem escrever o nome os objetos ou apenas repetir o nome do objeto falado no vídeo. Os professores que vão utilizar esse material, como acontece com qualquer material didático, certamente terão que observar como podem favorecer a participação dos alunos e com isso propiciar a aprendizagem.

As propostas que apontamos aqui são exemplos de situações comunicativas, de como os alunos são protagonistas nas interações, e de que devem dar seus depoimentos reais de modo significativo.

Além do desenvolvimento de situações comunicativas, as unidades didáticas do material apresentam também momentos de percepção da própria cultura. Os hábitos de muitas comunidades falantes de Talian, embora exista diferença geográfica (SC, RS, PR, 
ES), podem ser muito semelhantes. Oportunizar esta observação, como, por exemplo, o fato de os falantes terem hábitos alimentares parecidos, auxilia na compreensão de si mesmos como falantes de Talian no Brasil. Além da alimentação, muitos outros aspectos culturais são semelhantes entre os falantes e aparecem como temas nas unidades didáticas, por exemplo, os encontros familiares (casamentos, festas, velórios) e a organização do espaço físico nas residências. A apresentação destes elementos no material oportuniza aos falantes a percepção de que além da língua, hábitos culturais são compartilhados por falantes de Talian no Brasil. É possível também, a partir da proposta do material, fazer relações entre as práticas culturais do Talian no Brasil e as práticas culturais vênetas da Itália, observando as modificações e ‘adaptações' feitas pelos falantes aqui no Brasil.

Os recursos linguísticos ou itens gramaticais também estão presentes, mas em formato de tarefas que visam à reflexão sobre como são usados nas interações comunicativas. Se for de interesse dos alunos e do professor, poderá haver explicações mais detalhadas sobre esses itens.

\section{CONSIDERAÇÕES FINAIS}

O presente trabalho teve como objetivo apresentar aspectos, sobretudo metodológicos, da produção de um material didático para o ensino de Talian como língua de herança no Brasil. Para tanto, foi necessário esclarecer conceitos importante como língua de herança, por exemplo. É fundamental perceber também que para esta pesquisa o Talian é visto como uma língua que nasce em terras brasileiras e que, como toda língua, apresenta suas variações. Além da apresentação destes conceitos, foram expostas as teorias referentes à metodologia de ensino subjacentes ao presente material, são elas: ensino por tarefas e ensino intercultural. Tais abordagens teóricas contribuíram para o desenvolvimento do material porque são abordagens que permitem a prática comunicativa em situações reais ou verossímeis, a valorização das variações do Talian, a elaboração de atividades que promovam a observação da sua própria cultura, a prática de vocabulário, da forma linguística e de diversos aspectos culturais.

Finalmente foram demonstradas as estruturas das unidades didáticas, ou seja, como elas são compostas e como foram pensadas para a promoção e a manutenção da língua Talian. Também são fornecidas informações sobre os possíveis contextos de uso do material e seu possível público-alvo. Além disso, compartilhamos desafios vivenciados e questões que estão sendo analisadas.

Embora ao preparar esse material didático tenhamos imaginado o momento da 
sua aplicação, e para isso projetamos atividades e tarefas que possam ser favoráveis à aprendizagem, sabe-se que a implementação de qualquer material vai depender de várias condições, entre elas e talvez a mais importante: a formação do professor. No entanto, espera-se que esse material didático contribua para a divulgação, a aprendizagem e a manutenção da língua e da cultura taliana do Brasil. 


\section{REFERÊNCIAS:}

BALBONI, Paolo E. Dizionario di glottodidattica. Perugia: Guerra, 1999.

BALTHAZAR, Luciana Lanhi. Atitudes linguísticas de italo-brasileiros em Criciúma (SC) e região. 298 f. Tese (Doutorado em Letras), Setor de Ciências Humanas, da Universidade Federal do Paraná, Curitiba, 2016.

BALHANA, Altiva P. Santa Felicidade: uma paróquia veneta no Brasil. Curitiba: Fundação Cultural, 1978.

DEGACHE, Christian; MELO, Silvia. Un concept aux multiples facettes. Les Langues Modernes, Dossier: L'Intercompréhension, p. 7-14, 2008.

FREIRE, Paulo; FAUNDEZ, Antônio. Por uma Pedagogia da Pergunta. 3. ed. Rio de Janeiro: Paz e Terra, 1985.

FREIRE, Paulo. Pedagogia da esperança. Rio de Janeiro: Paz e Terra, 1992.

FREIRE, Paulo. Pedagogia da esperança: um reencontro com a pedagogia do oprimido. 2. ed. Rio de Janeiro: Paz e Terra, 1993.

FREIRE, Paulo. Pedagogia dos sonhos possíveis. São Paulo: UNESP, 2001.

FROSI, Maria Vitalina et al. Estigma: cultura e atitudes linguísticas. Caxias do Sul: Editora da Universidade de Caxias do Sul (EDUCS), 2010.

ELLIS, Rod. Task-based language learning and teaching. Oxford: OUP, 2003.

ESTAIRE, Sheila. El aprendizage de línguas mediante tareas: de la programação al aula. Madrid: Edinumen, 2009.

HYMES, Dell, On Communicative Competence. In PRIDE, J. B.; HOLMES, J. Sociolinguistics. England: Penguin Books, 1972. p. 269-293.

KRAMSCH, Claire. Context and Culture in Language Teaching. Oxford: Oxford University Press, 1993.

KRAMSCH, Claire. Cultura no ensino de língua estrangeira. Bakhtiniana, Rev. Estud. Discurso, São Paulo, v. 12, n. 3, p. 134-152, set./dez. 2017. Disponível em: <https:// www.scielo.br/scielo.php?script=sci_arttext\&pid=S2176-45732017000300134\&lng=pt \&nrm=iso>. Acesso em 28 jun. 2020. http://dx.doi.org/10.1590/2176-457333606. 
LARAIA, Roque de Barros. O legado da antropologia brasileira: relato de Roque de Barros Laraia. Horiz. antropol., Porto Alegre, v. 20, n. 42, p. 361-376, jul./dez. 2014. Disponível em: $\quad<$ http://www.scielo.br/scielo.php?script=sci_arttext\&pid=S010471832014000200014\&lng=en\&nrm=iso $>$. Acesso em 29 jun. 2020. https://doi. org/10.1590/s0104-71832014000200014.

LUCE, Maurício. Seibel; FINGER, Ingrid. O ensino de línguas por tarefas: um exemplo prático de sequências didáticas e o papel da saliência de elementos de gênero e de aspectos gramaticais nas etapas de pré e pós-tarefas. Revista Língua \& Literatura, v. 10, n 15, p. 19-41, dez. 2008.

NUNAN, David. Designing tasks for the communicative classrooms. Cambridge: Cambridge University Press, 1989.

ORTALE, Fernanda. Landucci. A formação de uma professora de italiano como língua de herança: o pós-método como caminho para uma prática docente de autoria. $162 \mathrm{p}$. Tese (Livre Docente em Língua Italiana) - Faculdade de Filosofia, Letras e Ciências Humanas, Universidade de São Paulo, São Paulo, 2016.

PRABHU, N. S. Second Language Pedagogy: Oxford: Oxford University Press. 1987.

RAJAGOPALAN, Kanavillil. Por uma linguística crítica - linguagem, identidade e a questão ética. São Paulo: Parábola, 2003.

SANTOS, Jovania Maria Perin. Propostas de critérios para elaboração de unidades temáticas e de enunciados de tarefas em contexto de ensino de PLE no Celin-UFPR. 149 f. Dissertação (Mestrado em Estudos Linguísticos) - Setor de Ciências Humanas, Universidade Federal do Paraná, Curitiba, 2014.

TARALLO, Fernando. A pesquisa sociolinguística. São Paulo: Ática, 1985.

WILLIS, Jane. A Flexible framework for task-based learning. In: WILLIS, J.; WILLIS, D. (Eds.) Challenge and change in language teaching. Oxford: Heinemann, 1996. p. 5262.

XAVIER, Rosely Perez. Metodologia do Ensino de Inglês. Florianópolis: LLE/CCE/ UFSC, 2012. 


\section{ANEXOS}

\section{ANEXO 1: UNIDADE DIDÁTICA: O QUE VOCÊ FAZ NO DOMINGO DE MANHÃ?}

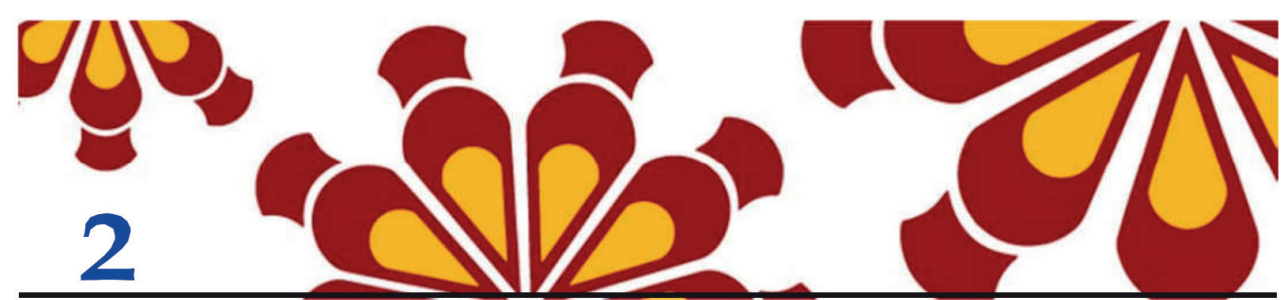

O que você faz no domingo demanhã?

प) 1. Ouça os áudios e relacione com as imagens.
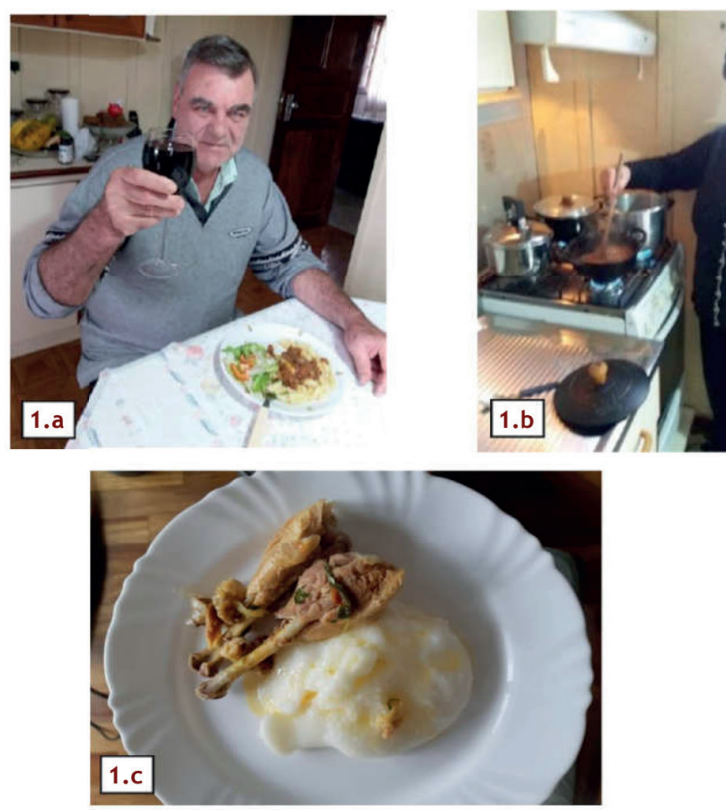

ชి Interação

a. A que horas você se levanta no domingo?

b. O que você normalmente faz nos domingos de manhã?

c. Tem alguma feira perto da sua casa aos domingos? Essa feira é muito frequentada? O que é possível comprar?

0 que você gosta de comprar nessa feira?

d. Que dia da semana você encontra os seus parentes?

E em que lugar?

e. As pessoas que você ouviu nos áudios falam da mesma forma?

Responda em Talian

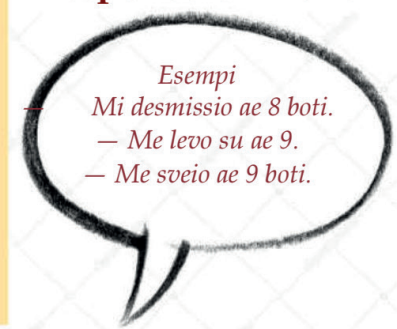




\section{Pra começar!}

2. Observe as imagens abaixo, discuta com os colegas qual será o assunto dovídeo.
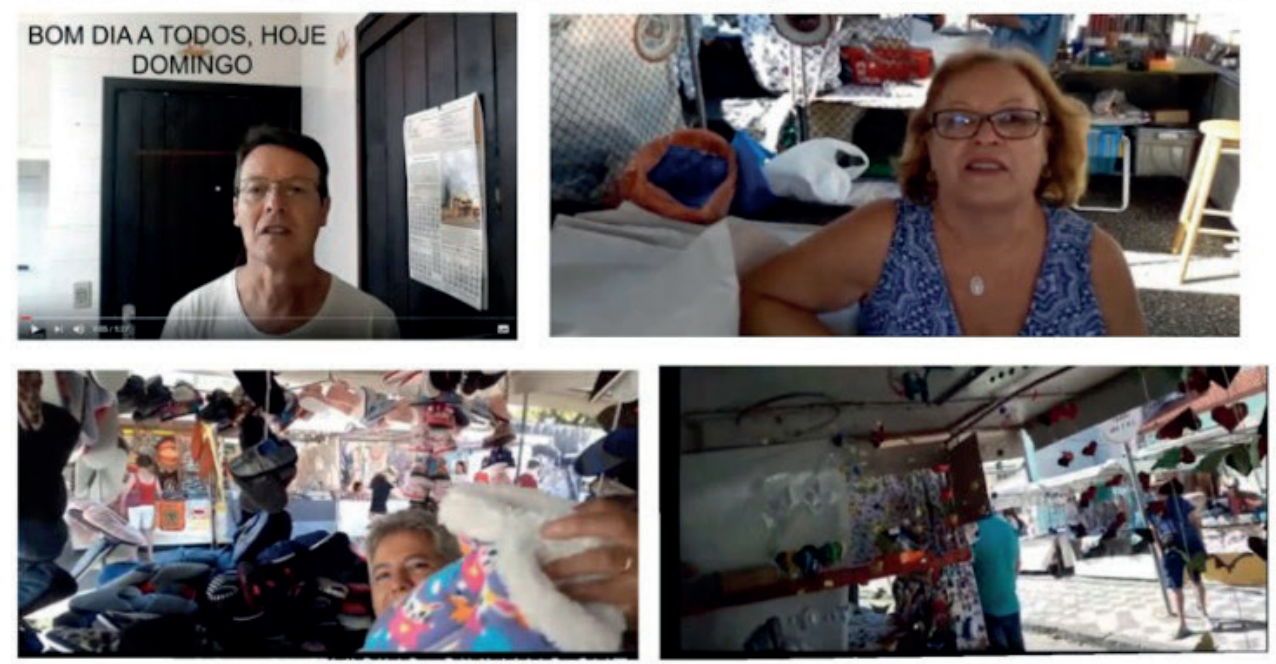

Fonte: https://www.youtube.com/watch?v=7vcvnx6sRK4\&feature=youtu.be\&app=desktop

昍 Compreensão do vídeo

3. Assista ao vídeo e responda as perguntas.

a. Procure na internet quem fez esse vídeo.

b. Onde ele mora?

c. 0 que ele vai fazer na feira?

d. Que igreja aparece no vídeo?

e. Como a irmã do Sr. Tulio faz os produtos quevende?

\section{Responda em Talian}

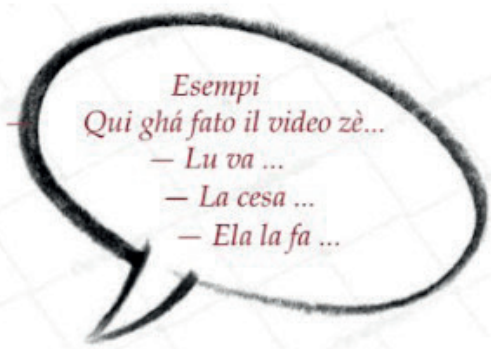

\section{$\equiv$ Como se diz em Talian?}

$\overline{\text { 4. Escreva como você chama esses objetos e compare com o que foi falado no vídeo. }}$
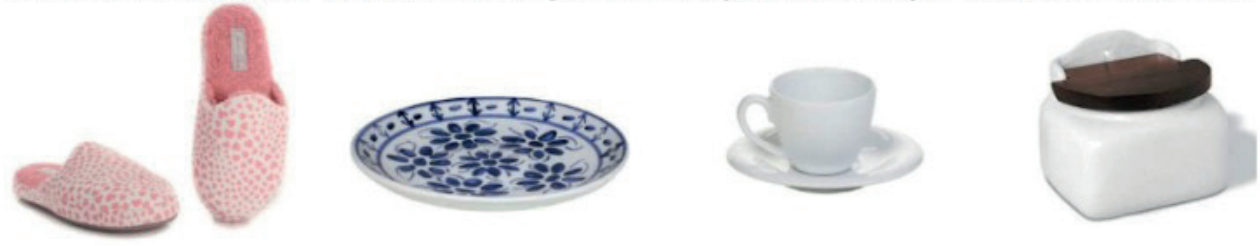

Diteitos autorais reservados ao Cevep (Centro de Estudos Vênetos no Paraná). Material didático gratuito. 


\section{O. Refletindo com o talian}

5. Leia o que o Sr. Tulio falou no começo do vídeo e desenvolva as atividades abaixo:

-Bondì a tuti. Oncòze doménega. Vaoa la fera parvédre mesoréla che'alaora là ntea praça Garibaldi in Curitiba ela vende la porselana che ela stessa la pinta. 'Demo farghe na visita e védre se compremo qualche robeta. 'Demo insieme!

\section{Responda em Talian}

a. O Sr. Túlio começa falando "bon dì a tuti". Você conhece outras formas de cumprimentar?

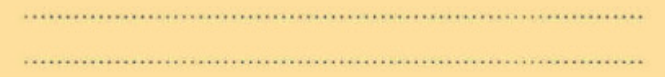

b. Você conhece os dias da semana? Complete a lista com um colega: Doménega

\section{Existem variações entre o que você} e seu colega falam? c. Na frase "ela stessa la pinta". A quemele está se referindo?

d. Crie outras frases com a expressão "stessa" sobre você e compare com um colega. Relatem à classe.

Existem variações entre o que você e seu colega falaram?

Como você fala "eu, tu, você, ele, ela, nós, vocês, eles e elas"?

e. Quem faz o quê? Relacione as ações do quadro abaixo às pessoas do texto, como no exemplo:

vao - laora -vende - pinta - ‘demo - compremo
Eu (........mi
Ela

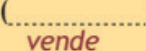
Nós ( ). vende

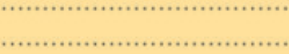

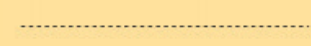

(a)

(a)

\section{$\equiv$ Como se diz em Talian?}

6. Escreva ou fale as ações:
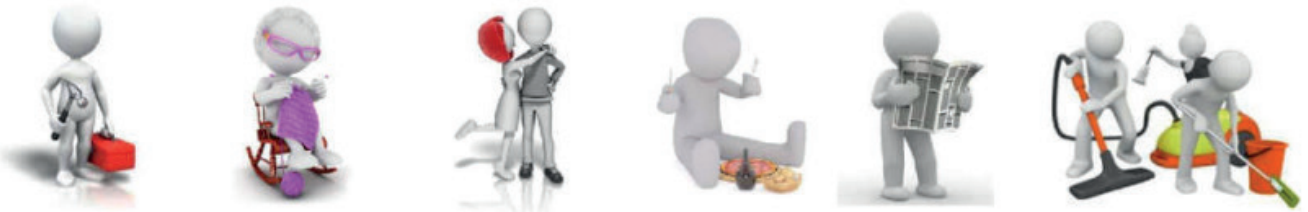

Laorar 


\section{Hora da música}

7. A música "A stimana" é cheia de rimas com os dias da semana. Leia as palavras do quadro abaixo e complete os versos da letra, como no exemplo:

dolor - inrabiato - capeo - Vicenza - porton - ciuca - seguente - bodega

\section{'A stimana}

Lune di poi go fato 'na .......... ......, 'na granda barufa, no vao laorar $(2 x)$

Marti di poi zè el giorno. no voio far gnente, no vao laorar $(2 x)$

Mèrcore di poi go perso el . e giusto per queo, no vao laorar $(x)$

Dóbia di poi ghenè festa $a$. bizogna pasiensa, no vao lavorar $(2 \mathrm{x})$

Vendre di poi zè giorno di zè morto el signor, no vao laorar $(2 \mathrm{x})$

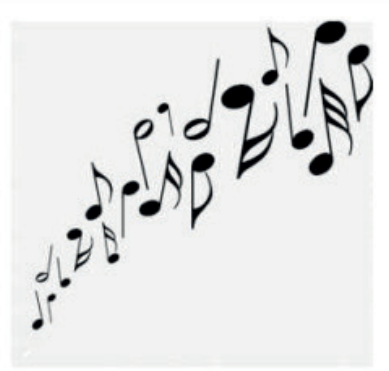

Sabo di poi mi so'a

mi sento in carega, no vao laorar $(2 x)$

8. Ouça a música e verifique as suas respostas.

Domènega di poi mi vao so'l

speto el paron, che vegna me pagar $(2 \mathrm{x})$

Riva el paron tuto

bruto vegliaco, và ti via di qua $(2 x)$

8. Complete a tabela com as informações da música e as suas atividades semanais, comono exemplo. Verifique com um colega se vocês fazem as mesmas coisas.

\begin{tabular}{|l|l|l|}
\hline Dias da semana & \multicolumn{1}{|c|}{ Música } & Eu \\
\hline Lune & Go fato 'na ciuca & \\
\hline Mèrcore & & \\
\hline & Ghenè festa a Vicenza & \\
\hline & & \\
\hline Sabo & & \\
\hline & & \\
\hline
\end{tabular}

9. Segundo o provérbio o que representa a quinta-feira? Que outras ações você associa aos dias da semana?

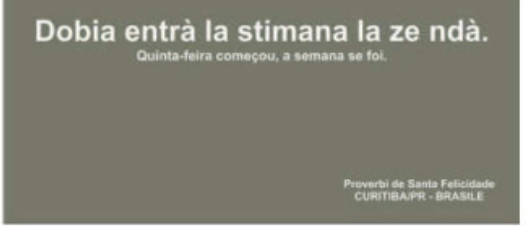




\section{O. Refletindo com o talian}

10. Leia o que diz o $\mathrm{Sr}$. Tulio e indique a imagem descrita por ele.

-[Dirnei Tulio]Bon,zemassabonóra. Ghezepocaiententeastrada. Zequindesepa'e nove. Ma da quà a na s-cianta quà va èssere pien de iente.
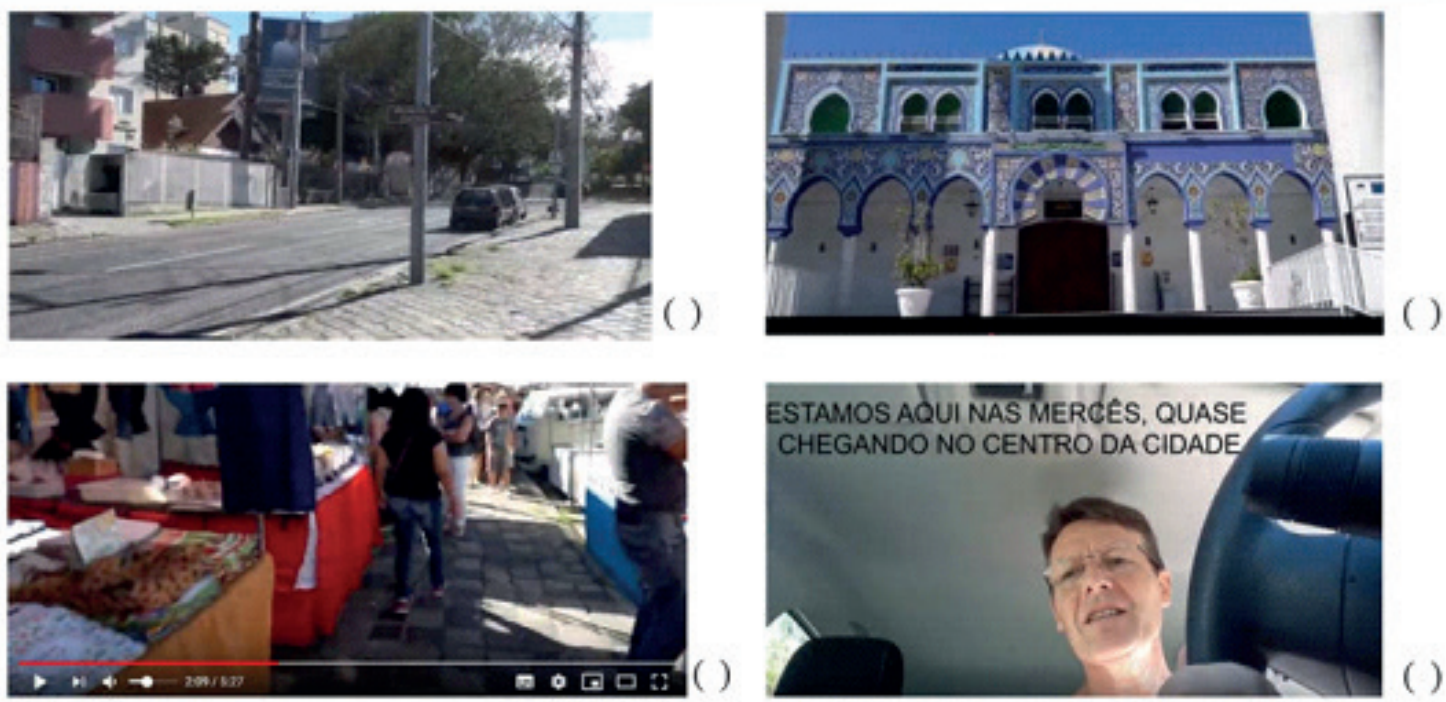

đ)) Escuta só

11. 0 áudio a seguir descreve uma cidade. Ouça e assinale somente os lugares que sãocitados.
a. ( ) igreja
e. ( ) piscina pública
i. ( ) parque
b. ( ) teatro
f. ( ) gruta
c. ( ) escola
g. ( ) cantina
d. ( ) praça
h. ( ) campo de futebol
j. ( ) feira livre
k. ( ) museu
l. ( ) panificadora

12. Ouça o áudio novamente e responda as questões:
a. Você conhece essa cidade?
b. Onde fica?
c. 0 que tem nessa cidade?
d. Como é a igreja?
e. 0 que as pessoas fazem no parque?
f. O que não falta na cidade?
g. Qual é o lugar mais conhecido da cidade?

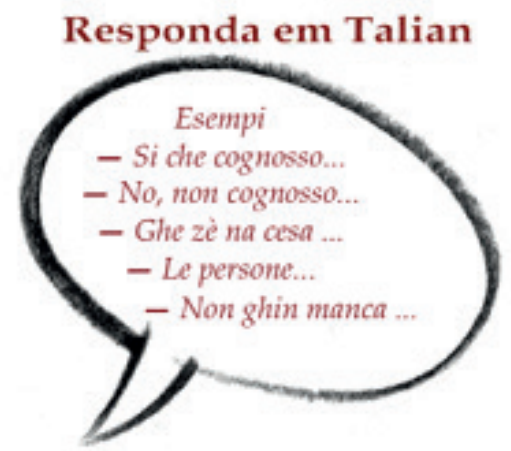

